\title{
Amino-calixarene-modified graphitic carbon as a novel electrochemical interface for simultaneous measurement of lead and cadmium ions at picomolar level
}

\author{
Prashanth Shivappa Adarakatti ${ }^{1}$ Pandurangappa Malingappa ${ }^{1}$
}

Received: 13 April 2016 /Revised: 20 June 2016 / Accepted: 22 June 2016

(C) Springer-Verlag Berlin Heidelberg 2016

\begin{abstract}
Amino-calixarene-derivatized graphitic carbon electrode has been used in the simultaneous quantification of lead and cadmium ions at picomolar level. The graphitic carbon has been chemically modified using amino-calixarene as an indicator molecule through microwave irradiation, and it has been characterized by NMR, mass, and Fourier transform infrared spectroscopy (FTIR) techniques. The proposed sensor has shown linearity in the concentration range $10-120 \mathrm{pM}$ with detection limits of 3.3 and $3.5 \mathrm{pM}$ for lead and cadmium, respectively. The proposed sensor has been successfully applied to quantify lead and cadmium levels in battery effluents, alloy materials, and sewage water sample matrices. The results obtained by the proposed sensor are in agreement with the results of the standard protocols.
\end{abstract}

Keywords Amino-calixarene - Graphitic carbon · Anodic stripping voltammetry $\cdot$ Lead $\cdot$ Cadmium $\cdot$ Battery effluents

\section{Introduction}

Toxicity due to heavy metal ion presence such as lead and cadmium in groundwater has been a major concern in recent years all over the world [1]. The presence of these metal ions in the environment in larger concentration is mainly due to the

Electronic supplementary material The online version of this article (doi:10.1007/s10008-016-3306-4) contains supplementary material, which is available to authorized users.

Pandurangappa Malingappa mprangachem@gmail.com

1 Department of Studies in Chemistry, Bangalore University, Central College Campus, Bengaluru 560001, India increased human activity in various industrial processes like metallurgical, catalytic, polymer, dye, and fertilizer industries. Because of their high toxicity and prolonged exposure, even at trace-level concentration, these metal ions can cause severe problems in human and aquatic systems [2]. Lead and cadmium have acute and chronic effects on human health. The presence of lead in the environmental samples like water, air, and soil samples may cause neurological, cardiovascular, and reproductive disorders in human kind. The presence of cadmium in water samples may lead to kidney damage; subsequently, it can alter the constitution of the bone, liver, and blood [3]. The prescribed threshold limit values (TLV) of lead and cadmium ions in drinking water are 10 and $3 \mathrm{ppb}$, respectively, according to the World Health Organization [4]. Hence, it is mandatory to measure these metal ions at ultra trace-level concentration in order to check the quality of drinking water by several governmental and non-governmental agencies [5]. Several protocols have been reported to quantify these metal ions at bulk concentration level. However, the trace-level quantification is a major challenging problem due to the sophisticated instrumentation involved, skilled operators, very tedious sample preparation procedures, etc. Several techniques like flame atomic absorption spectrometry (FAAS), graphite furnace atomic absorption spectrometry (GFAAS), and inductively coupled plasma atomic emission spectrometry (ICPAES) have been routinely used to quantify these elements at ultra trace-level concentration from a variety of sample matrices [6-10]. But, all these techniques are expensive and require skilled personnel to operate and prolonged sample preparation procedures. However, electrochemical methods are possible alternative ones to these techniques due to their high sensitivity, selectivity, and wide variability in their modification strategies. They also provide very wide working linearity, portability, and low cost. Hence, in recent years, a significant emphasis has been laid in the development of 
electrochemical-based sensors in the quantification of several toxic and heavy metal ions [11]. A variety of electrodes have been used in the electrochemical quantification of both inorganic and organic analytes incorporating suitable indicator or modifier molecules on the surfaces of substrate materials. Among these, gold-coated electrodes, silver electrodes, glassy carbon electrodes, carbon paste electrodes, and screen-printed electrodes are significant ones to mention it here [12-22]. Chemically modified electrodes (CMEs) are another class of electrodes extensively used to achieve the target analyte selectivity and specificity based on modifying the carbon substrate surface with an indicator molecule containing electroactive moieties as a part of the molecular structure [23]. The chemical modification of various carbon substrates such as carbon nanotubes (CNTs), carbon nanohorns $(\mathrm{CNH})$, carbon nanofibers(CNF), graphene, graphite, glassy carbon spheres, and boron-doped diamond has been reported [24-30] for measurement of lead and cadmium ions. Poly(4-vinylpyridine-coaniline)-based solid-state ion sensor was used for cadmium(II) measurement from water and food samples [31]. A microtiter plate-based electrochemical device was developed and used in simultaneous measurement of lead and cadmium ions from standard effluent sample [32]. These electrodes were modified using several methods such as wet impregnation (physisorption), polymer wrapping, covalent attachment, chemisorption, etc. A chemically modified carbon paste electrode containing periodic mesoporous organosilica and cyclodextrins was used in the determination of lead and cadmium from water samples $[33,34]$. But, these methods are having limitations such as poor stability, low-adhesive nature, nonuniform distribution of modifier, and uncontrollable thickness of the film resulting in the poor reproducibility of the measurements [35].

Modification of carbon substrate with calixarene moiety has gained much attention in recent years due to their selective recognition and complexation with metal ions. Calixarenes and its derivatives with suitable functional moieties have been used as a sensing material in the electroanalysis of toxic metal ions recently [36, 37]. Mahajan et al. have used poly(vinylchloride) (PVC) matrix membrane based on Schiff base p-tert-butyl calix[4]arene derivative as an ion-selective electrode in silver(I) quantification [38]. Mandlier et al. have successfully extracted and quantified uranyl ions from aqueous solution using a self-assembled monolayer composed of cysteamine to which 4-sulfonic calixarene was electrostatically anchored on the surface of gold electrode [39]. Similarly, Hanna et al. have used ferrocene-substituted calixpyrrole as a neutral redox-active receptor incorporating into carbon paste electrode to recognize anions such as $\mathrm{F}^{-}, \mathrm{Cl}^{-}, \mathrm{Br}^{-}$, and $\mathrm{H}_{2} \mathrm{PO}_{4}{ }^{-}$in aqueous medium [40]. Hart et al. have used calixarene derivatives as an indicator molecule in the determination of $\mathrm{Pb}^{2+}$ and $\mathrm{Cd}^{2+}$ ions using screen- printed carbon electrodes [21, 22]. Zazoua et al. have used cadmium-sensitive electrode based on tetraacetone derivative of calixarene moiety using electrochemical impedance spectroscopy [41]. In the present report, aminocalixarene-modified graphitic carbon has been used as a novel electrochemical interface to quantify lead and cadmium ions simultaneously at trace level from various sample matrices using cyclic voltammetry and differential pulse anodic stripping voltammetry (DPASV) techniques.

\section{Experimental}

\section{Chemicals and reagents}

All reagents used were of Analar grade and used without any further purification. Graphite (dia. $<20 \mu \mathrm{m}$ ), lead nitrate, cadmium nitrate, and potassium bromide (Fourier transform infrared spectroscopy (FTIR) grade, purity, $99.99 \%$ ) were obtained from Sigma-Aldrich. Acetic acid, sodium acetate, and sodium hydroxide were purchased from SD Fine Chemicals, Mumbai. All pH solutions in the range 2-8 were prepared using ultra pure doubledistilled water from Millipore water purifier with a resistivity of not less than $18.2 \mathrm{M} \Omega \mathrm{cm}^{-1}$ at $25{ }^{\circ} \mathrm{C}$. Stock solutions of lead and cadmium ionic solutions were prepared using corresponding salts. Working standards were prepared by diluting the stock solutions on the day of use.

\section{Apparatus}

All electrochemical measurements were carried out using an electrochemical workstation [ $\mathrm{CH}$ Instruments, $\mathrm{TX}$, USA, model: CHI 619B] at room temperature $(25 \pm$ $2{ }^{\circ} \mathrm{C}$ ) in an electrochemical cell of volume $10 \mathrm{~mL}$ with a standard three-electrode configuration. Chemically modified glassy carbon electrode (dia. $=5 \mathrm{~mm}$ ) acted as the working electrode and $\mathrm{Ag} / \mathrm{AgCl}(3 \mathrm{M} \mathrm{KCl})$ as a reference electrode ( $\mathrm{CH}$ Instruments, TX, USA). Platinum wire acted as the counter electrode. All the solutions were degassed using high-purity nitrogen gas for $10 \mathrm{~min}$ before all electrochemical measurements. All pH measurements were carried out using a $\mathrm{pH}$ meter (Control Dynamics, Mumbai, India model: APX 175). Infrared measurements were recorded using FTIR spectrometer (Bruker, model: $8400 \mathrm{~S}$ ) in the range $400-4000 \mathrm{~cm}^{-1}$ with a resolution of $4 \mathrm{~cm}^{-1}$. Microwave experiments were conducted using a domestic microwave oven. ${ }^{1} \mathrm{H}$ NMR spectra were recorded using400-MHz NMR spectrometer (Bruker) using dimethylsulfoxide (DMSO-d6) as solvent and tetramethylsilane (TMS) as an internal standard. The mass spectral data was recorded using GCMS (Shimadzu, Japan, model: QP 2010S). 


\section{Analytical procedure}

The simultaneous determination of $\mathrm{Pb}^{2+}$ and $\mathrm{Cd}^{2+}$ ions was carried out using DPASV in the potential range from -1.0 to $0.0 \mathrm{~V}$ with an amplitude of $0.01 \mathrm{~V}$ and a pulse width of $0.05 \mathrm{~s}$. Known amounts of both lead and cadmium ions were taken in an electrochemical cell of $10-\mathrm{mL}-$ volume capacity containing $4 \mathrm{~mL}$ of sodium acetateacetic acid buffer solution ( $\mathrm{pH}$ 6) and $4 \mathrm{~mL}$ of $1 \mathrm{M}$ potassium nitrate, which is fitted with a tab-controlled magnetic stirrer. The CME was immersed into the abovestirred solution for $2 \mathrm{~min}$ to preconcentrate the metal ions at open circuit potential. Then, the preconcentrated metal ions were reduced at a reduction potential of $-1.2 \mathrm{~V}$ and subsequently stripped off from the electrode surface into the bulk of the electrolytic solution by sweeping the potential in the positive direction after $20 \mathrm{~s}$ of equilibration time. Then, the modified electrode is gently washed with a small quantity of distilled water for further use.

\section{Synthesis of modifier}

Calixarene was prepared using p-tert-butylphenol and formaldehyde as per the reported literature method [42]; subsequently, $1 \mathrm{~g}$ of calixarene $(1.54 \mathrm{mM})$ was taken in $100-\mathrm{mL}$ round-bottom flask to which $20 \mathrm{~mL}$ of conc. nitric + sulfuric acid mixture (1:1) was added and stirred at $10{ }^{\circ} \mathrm{C}$ for $24 \mathrm{~h}$. Yellow-colored solid obtained was filtered after the addition of $80 \mathrm{~mL}$ of distilled water. Then, it was washed with methanol and dried at room temperature. The obtained solid was recrystallized using acetone [43]. Then, in order to reduce the nitro to amino calixarene, $5 \mathrm{mg}$ of nanopalladium/carbon composite was added under hydrogen atmosphere into $50-\mathrm{mL}$ flask containing $1 \mathrm{~g}$ of p-nitrocalixarene and the reaction mixture was stirred for $15-30 \mathrm{~min}$. Then, the reaction mixture was cooled at room temperature to obtain the desired product (Scheme 1).

\section{Characterization}

The prepared compounds of calixarene and amino-calixarene were characterized by spectroscopic tools to ascertain the functional groups as well as its molecular mass.

\section{FTIR study}

The infrared spectra of calixarene and amino-calixarene were recorded in the wave number range $4000-400 \mathrm{~cm}^{-1}$ to confirm the presence of functional groups in the synthesized molecule. A weak stretching frequency was observed at $3166 \mathrm{~cm}^{-1}$ due to the vibration of $\mathrm{OH}$ groups of cyclic tetramer. The bands at 1449 and $1391 \mathrm{~cm}^{-1}$ might be due to the $\mathrm{COH}$ bending vibrations (Fig. 1). The spectrum of aminocalixarene (Fig. 2) showed a band at $1342 \mathrm{~cm}^{-1}$ corresponding to the $-\mathrm{C}=\mathrm{N}-$ stretching and the band at $1530 \mathrm{~cm}^{-1}$ due to $-\mathrm{N}-$ $\mathrm{H}$ bending and $3285 \mathrm{~cm}^{-1}-\mathrm{N}-\mathrm{H}$ stretching, which were not found in the spectrum of calixarene. These results confirmed the presence of amino groups on the calixarene moiety.

\section{GC-MS study}

The synthesized calixarene molecule and its molecular mass were determined by the GC-MS study. A molecular ion peak at $m / z 648$ (Fig. 3) was observed, which corresponds to the molecular weight of the synthesized compound. The peak observed at $\mathrm{m} / \mathrm{z} 592$ is due to the loss of one tert-butyl group from one of the upper rims of the compound.

\section{${ }^{1}$ H NMR study}

${ }^{1} \mathrm{H}-\mathrm{NMR}$ spectra were recorded using Bruker 400-MHz instrument with TMS as the internal standard and DMSO- $d_{6}$ as the solvent. A broad singlet observed at $8.69 \mathrm{ppm}$ corresponds to the four phenolic $-\mathrm{OH}$ groups of the calix[4]arene moiety. Methylene protons resonated at $3.80 \mathrm{ppm}$ as a singlet, whereas
Scheme 1 Synthesis of aminocalixarene

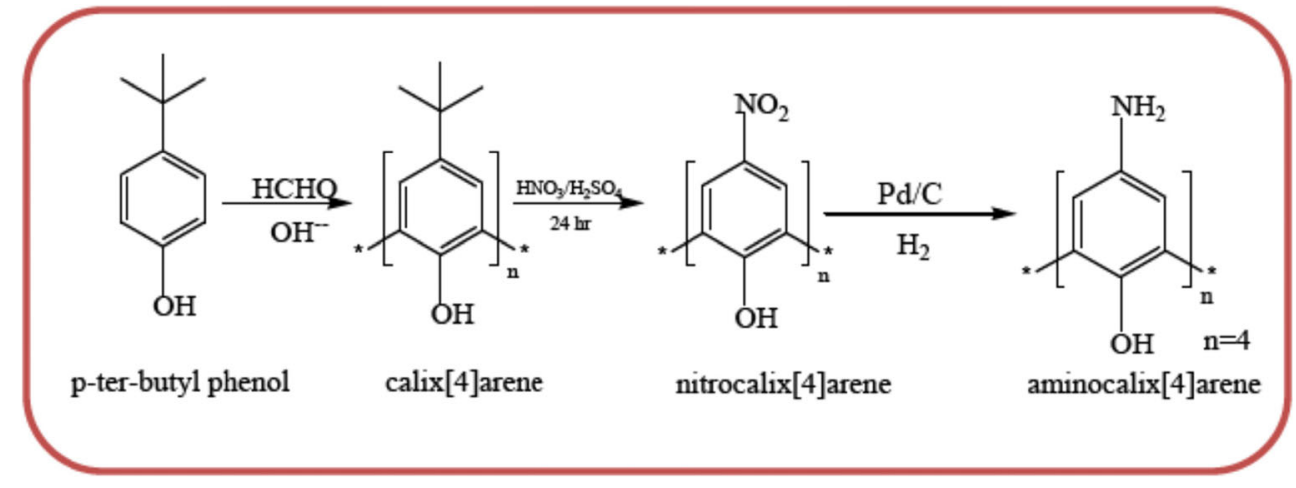




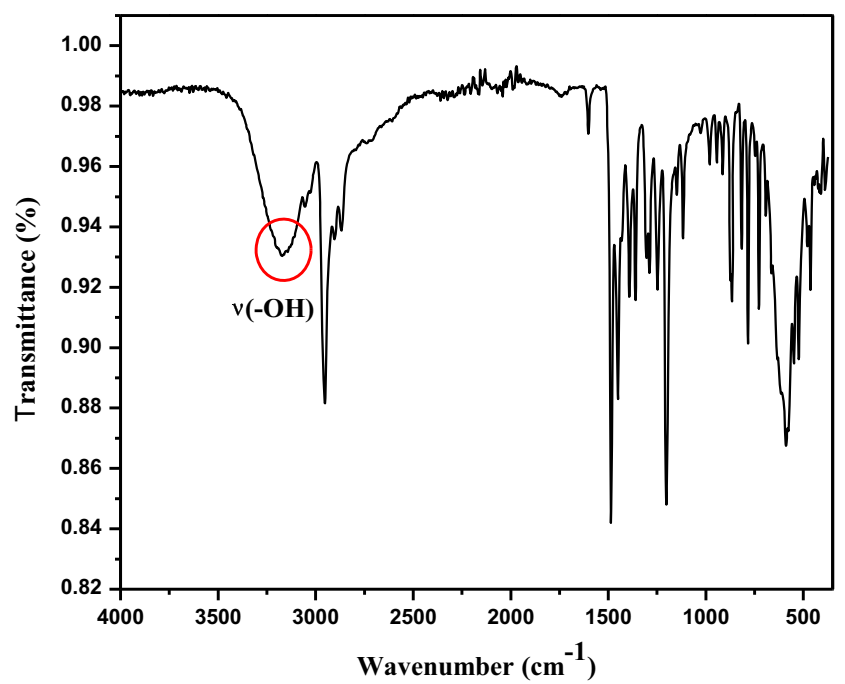

Fig. 1 FTIR spectrum of calixarene

the singlet observed at $1.09 \mathrm{ppm}$ corresponds to the methyl group of the tert-butyl moieties (Fig. 4).

\section{Covalent modification of graphitic carbon with amino-calixarene}

One gram of graphitic carbon powder in $100-\mathrm{mL}$ beaker containing $10 \mathrm{~mL}$ of conc. $\mathrm{HNO}_{3}$ was irradiated with microwave energy $(15 \%$ of total $600 \mathrm{~W})$ for about $2 \mathrm{~min}$ to induce carboxylic groups on the surface of graphitic carbon particles. Then, $500 \mathrm{mg}$ of amino-calixarene was added and irradiation was continued for two more minutes. The chemically modified graphitic carbon powder was washed thoroughly with acetonitrile several times to remove the unreacted and physisorbed modifier molecules. Then, the reaction mixture was washed with ample quantities of water to remove the excess of acid present in it. Finally, the carbon powder

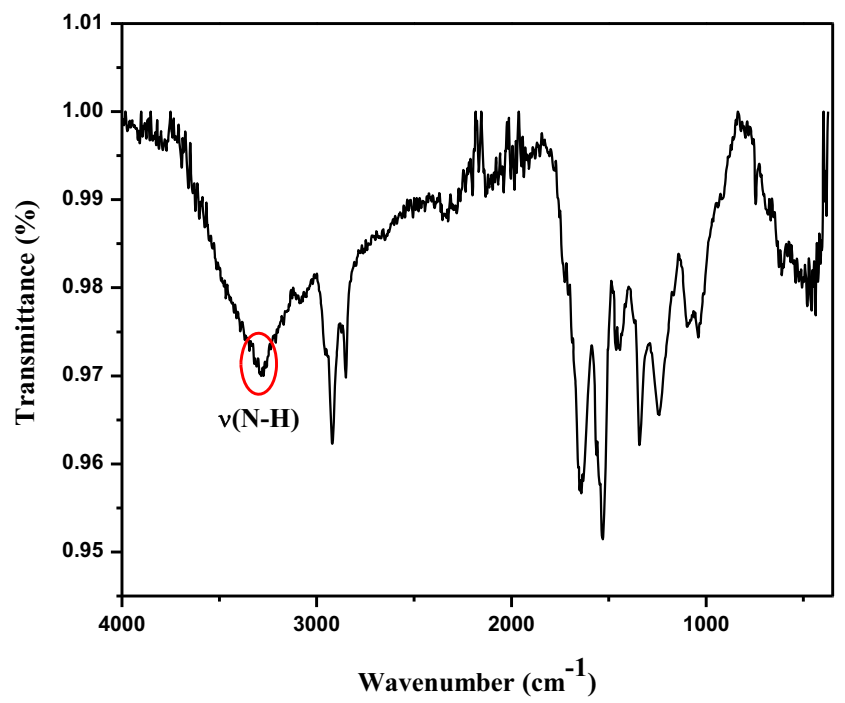

Fig. 2 FTIR spectrum of amino-calixarene particles were washed with acetone to remove the moisture. The functionalized carbon powder was dried by placing in a fume hood for a period of $10 \mathrm{~h}$ and stored in an airtight container prior to its use [44] (Scheme 2).

\section{Chemical modification of glassy carbon electrode}

Chemically modified graphitic carbon particles $(5 \mathrm{mg})$ were added into $5 \mathrm{~mL}$ of water in glass vial and sonicated for $30 \mathrm{~min}$ to achieve uniform dispersion. Then, $25 \mu \mathrm{L}$ of dispersed solution was drop casted onto the glassy carbon electrode (Scheme 3). The electrode was allowed to dry for a period of several hours to remove the solvent from the surface of electrode at ambient conditions. This procedure was repeated several times to get uniform distribution of modified graphite particles on glassy carbon electrode surface.

\section{Results and discussion}

\section{Electrochemical behavior of amino-calixarene-modified electrode}

The electrochemical response of amino-calixarene-modified electrode in presence of lead and cadmium ions was first examined using cyclic voltammetry technique in order to understand the potential affinity of the modifier molecule toward $\mathrm{Pb}^{2+}$ and $\mathrm{Cd}^{2+}$ in aqueous medium. The typical cyclic voltammetric response in presence and absence of metal ions at calixarene and amino-calixarene-modified interfaces in the potential window from -1.0 to $0.0 \mathrm{~V}$ is shown in Fig. $5(\mathrm{a}-\mathrm{d})$. The resulting voltammograms have showed well-defined oxidative and reductive peaks for the CME in presence of metal ions, indicating that the modifier molecule could be used in the quantitative study. The glassy carbon electrode modified with calixarene in absence of metal ions (Fig. 5 (a)) has not shown any anodic signals but showed a small cathodic split signal, which might be attributed to the fact that the electrode surface unevenness is caused by that during drop-casting method. However, the same electrode (Fig. 5 (c)) in presence of metal ions has shown well-defined oxidative and reductive peaks with small peak current intensities. But, the aminocalixarene-modified electrode exhibited strong oxidative peaks with increased peak currents in comparison with calixarene-modified interface. However, amino-calixarenemodified electrode in presence of metal ions showed significant anodic peaks and weak split cathodic peaks Fig. 5 (b). The splitting of cathodic signals of amino-calixarenemodified electrode in presence of electrolyte solution containing target analytes, i.e., $\mathrm{Pb}$ (II) and $\mathrm{Cd}$ (II) ions, was observed at a potential of -0.55 and $-0.80 \mathrm{~V}$, respectively. The splitting of cathodic peaks might be due to the uneven electrode surface formed during the drop-casting method. or it could also be due 


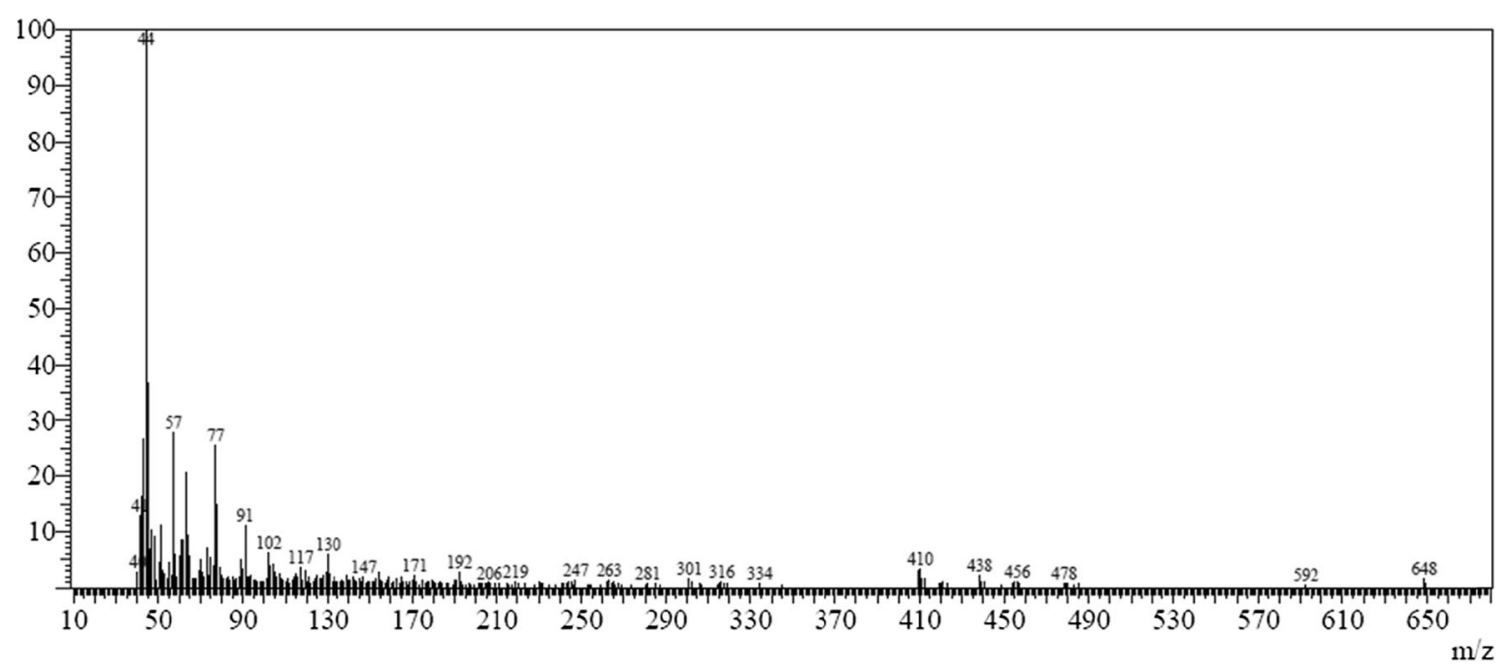

Fig. 3 GC-MS spectrum of calixarene

to any extraneous redox processes occurring during electrochemical study. The voltammogram of the unmodified electrode has been shown in Fig. 5 (d), and no splitting of the cathodic peaks was observed. These studies revealed that the chemically modified electrode (CME) surface could be efficiently used in the measurement of lead and cadmium ions simultaneously at trace level.

The oxidative peaks were significant in comparison with reductive peaks in the $\mathrm{CV}$ study; hence, to improve the measurement efficiency in the present protocol, the anodic stripping voltammetric technique was adapted in the current electrochemical study. The peak potentials in the stripping analysis have shifted toward more negative potential than in cyclic voltammetry due to the complexation phenomenon between the ligand molecules (CO-NH groups in the modifier molecule) and metal ions [45]. All these observations reveal that the working electrode modified with amino-calixarene as an indicator molecule could be used as a thin film in the

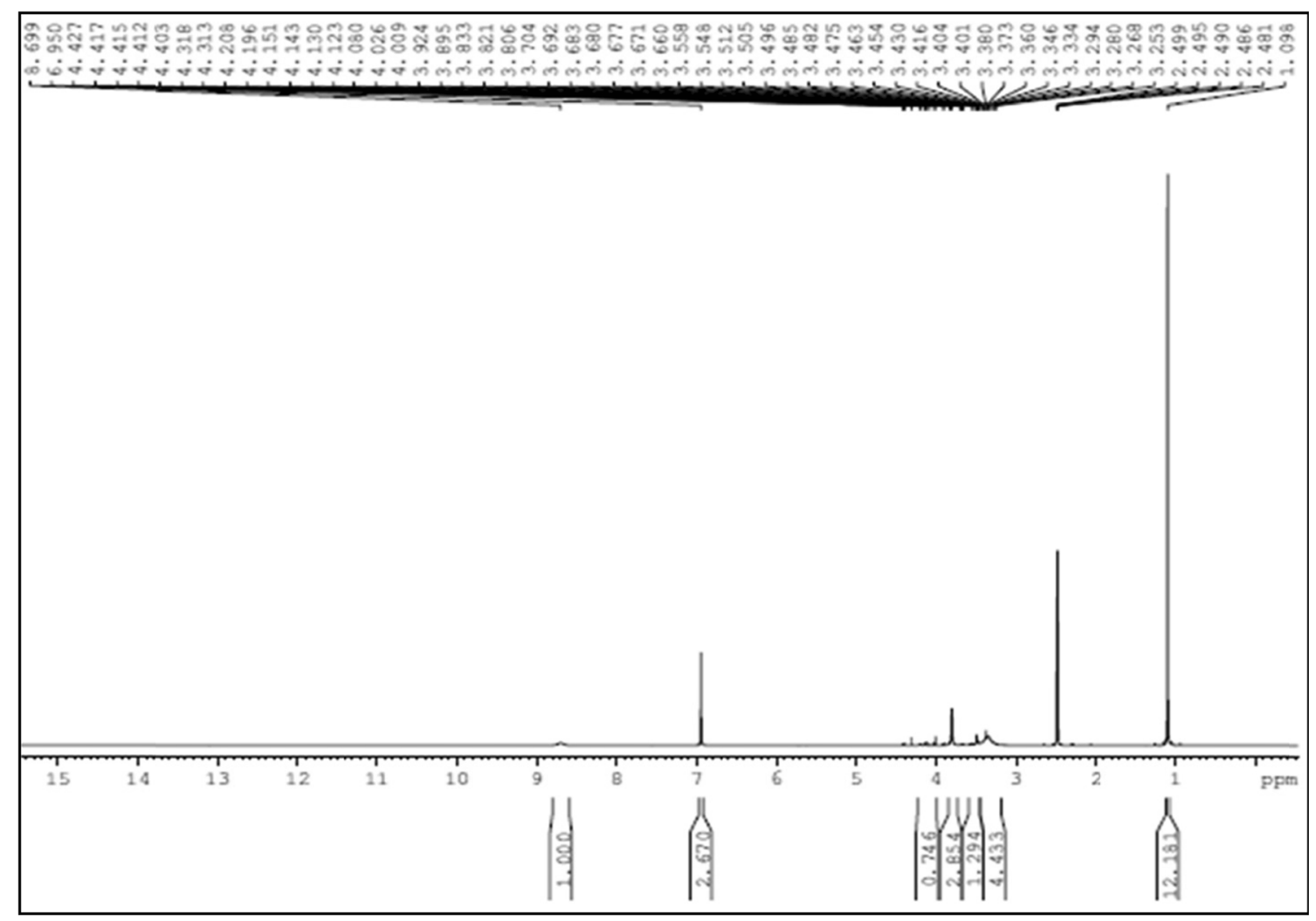

Fig. $4{ }^{1} \mathrm{H}$ NMR spectrum of calixarene 


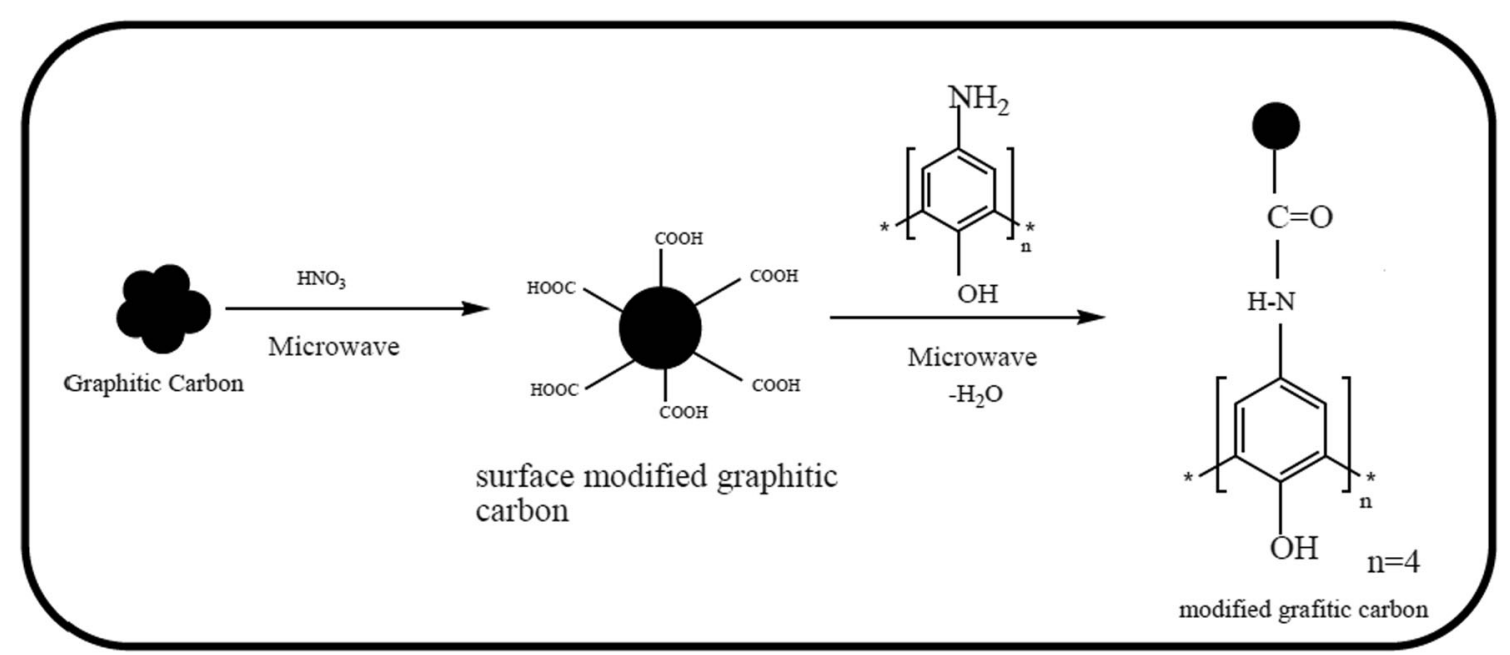

Scheme 2 Chemical modification of graphitic carbon powder

quantitative application study. In the proposed interface, the modifier molecule containing - $\mathrm{CONH}$ groups acts as a chelating agent, and during preconcentration step, metal ions accumulate on the electrode interface through complexation phenomenon. During electrochemical turnover, the accumulated metal ions will reduce to metallic state and subsequently gets oxidized to ionic state producing peak current proportional to the concentration of metal ions accumulated on the electrode interface [27]. The binding behavior and complexation mode between modifier molecule and the target metal ions are schematically shown in Scheme 4.

\section{Optimization study}

In order to achieve the maximum efficiency of aminocalixarene-modified electrode in the electrochemical quantification of $\mathrm{Pb}^{2+}$ and $\mathrm{Cd}^{2+}$ ions under aqueous medium, all the reaction variables like medium $\mathrm{pH}$, preconcentration time, and reduction potential were optimized.

\section{Effect of pH}

The effect of $\mathrm{pH}$ on the anodic stripping voltammetric (ASV) response of the modified electrode in the range $\mathrm{pH}$ 2-8 was investigated using $8 \mathrm{~mL}$ of $1 \mathrm{M} \mathrm{KNO}_{3}$ as supporting electrolyte and $1 \mathrm{~mL}$ of $1-\mathrm{mM}$ solutions of each of lead and cadmium ions. The desired $\mathrm{pH}$ was adjusted using acetate buffer solution. It was found that the peak current increased sharply with increasing $\mathrm{pH}$ up to 6 ; this is due to the increasing complex formation of lead and cadmium with chemically modified amino-calixarene electrode surface. At higher $\mathrm{pH}$, the decrease of the anodic peak currents might be the cause of hydrolysis, leading to the metal hydroxide formation. Hence, $\mathrm{pH}$ 6 was used as an optimum $\mathrm{pH}$ for the electrolyte in all further studies (Fig. 6).

\section{Effect of preconcentration potential}

The effect of the preconcentration potential on the anodic peak current of lead and cadmium ions was examined by varying the potential range from -0.6 to $-1.4 \mathrm{~V}$; well-defined peak currents were obtained. In this method, preconcentration can be achieved by keeping the electrode at particular potential in order to reduce the metal ions to their metallic state, which is reoxidized to their respective ions giving an anodic stripping peak during the anodic potential scan. The peak currents increase with increase of potential from -0.6 to $-1.2 \mathrm{~V}$ for lead and cadmium ions due to the reduction of more $\mathrm{Pb}^{2+}$ and $\mathrm{Cd}^{2+}$ ions. Further increase in the reduction potential from -1.2 to $-1.4 \mathrm{~V}$ leads to a steady-state current due to the hydrogen evolution at higher reduction potentials, which interfere in the determination of $\mathrm{Pb}^{2+}$ and $\mathrm{Cd}^{2+}$ ions [46-48]. Hence, a
Scheme 3 Chemical modification of glassy carbon electrode (GCE) surface by drop casting: $a$ bare electrode, $b$ modifier drop, and $c$ modified electrode surface

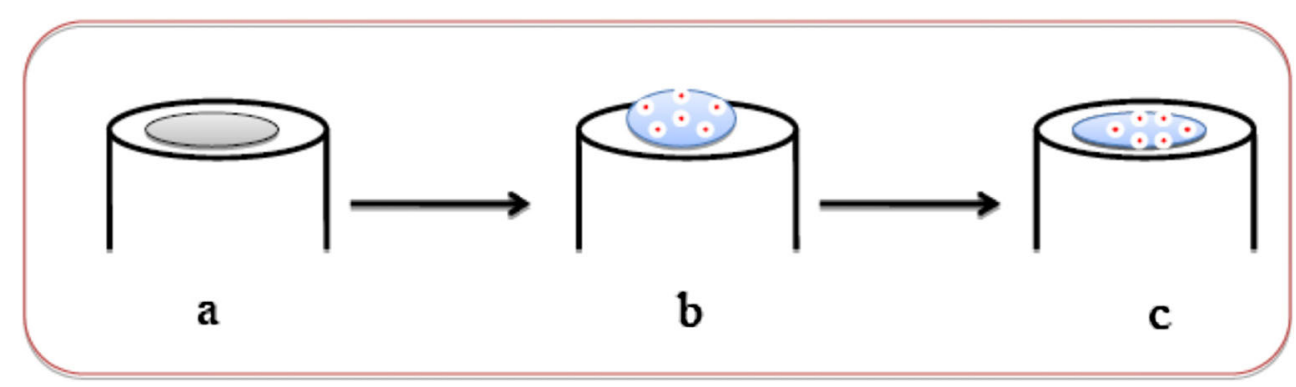




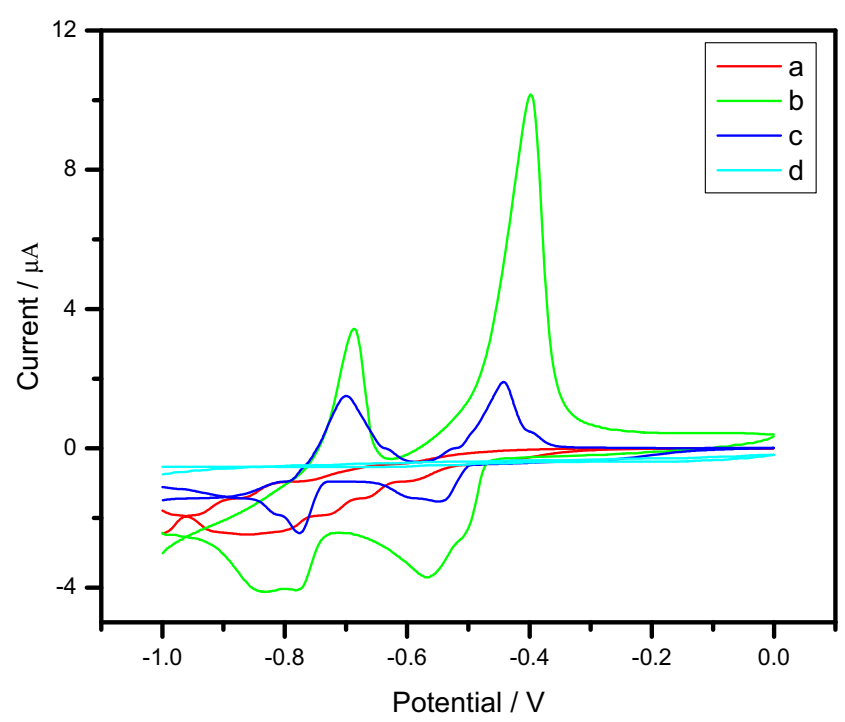

Fig. 5 Overlaid cyclic voltammograms of chemically modified glassy carbon electrode: $a$ calixarene-modified electrode in absence of metal ions, $b$ amino-calixarene-modified electrode, $c$ calixarene-modified electrode, and $d$ glassy carbon electrode in presence of 1-mM solution each of $\mathrm{Pb}^{2+}$ and $\mathrm{Cd}^{2+}$ ions in acetate-acetic acid buffer ( $\mathrm{pH}$ 6) containing $1 \mathrm{M} \mathrm{KNO}_{3}$ as supporting electrolyte. Scan rate, $100 \mathrm{mV} / \mathrm{s}$

reduction potential of $-1.2 \mathrm{~V}$ was used as the optimum condition in all further studies.

\section{Effect of preconcentration time}

The effect of time to preconcentrate the analyte species from the bulk of the solution to the electrode interface was studied. During this preconcentration step, the metal ions interact with the surface functional moieties through complexation and accumulate on the electrode surface. The effect of deposition time was studied between 1 and $7 \mathrm{~min}$ on the anodic stripping peak currents of $\mathrm{Pb}^{2+}$ and $\mathrm{Cd}^{2+}$. The dependence of the differential pulse anodic stripping peak current was carried out in a buffer solution of $\mathrm{pH} 6$ containing $1 \mathrm{M} \mathrm{KNO}_{3}$ as supporting electrolyte. The peak currents increase from 1 to $5 \mathrm{~min}$ and then remain almost constant after $5 \mathrm{~min}$. It might be due to the

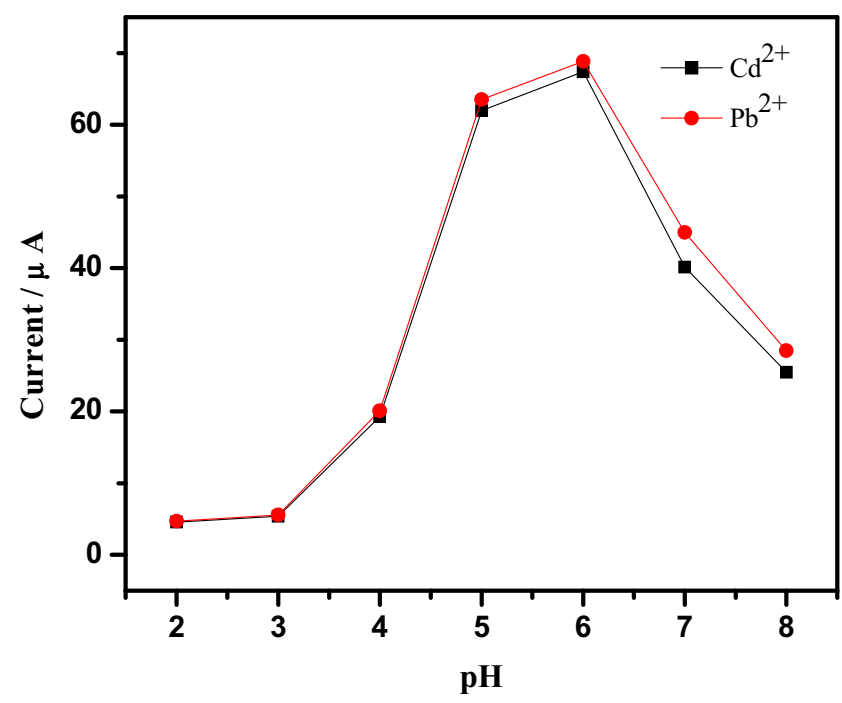

Fig. 6 Effect of $\mathrm{pH}$ on the anodic peak current observed for 1-mM concentration of each of $\mathrm{Pb}^{2+}$ and $\mathrm{Cd}^{2+}$ ions, preconcentration potential, $-1.2 \mathrm{~V}$; supporting electrolyte, $1 \mathrm{M} \mathrm{KNO}_{3}$

non-availability of sites on the electrode surface for the accumulation of metal ions, indicating the electrode surface saturation [34]. Hence, an optimum preconcentration time of 5 min was used in all further studies.

\section{Calibration plot}

The differential pulse anodic stripping voltammograms with the above-optimized conditions at different concentrations of lead and cadmium ions in presence of CME showed a linearity in the concentration range $10-120 \mathrm{pM}$ for $\mathrm{Pb}^{2+}$ and $\mathrm{Cd}^{2+}$ ions with detection limits of 3.3 and $3.5 \mathrm{pM}$, respectively. The experiments were repeated five times, and the concerned overlaid stripping voltammograms are shown in Fig. 7. The mathematical expressions for the calibration plots of target metal ions were found to be linear and given as lead ion $Y=(0.0054$ $\pm 0.0004) x+(1.02 \pm 0.03) R^{2}=0.984$ and cadmium ion $Y=(0.0146 \pm 0.0012) x+(0.15 \pm 0.09) R^{2}=0.983$. The

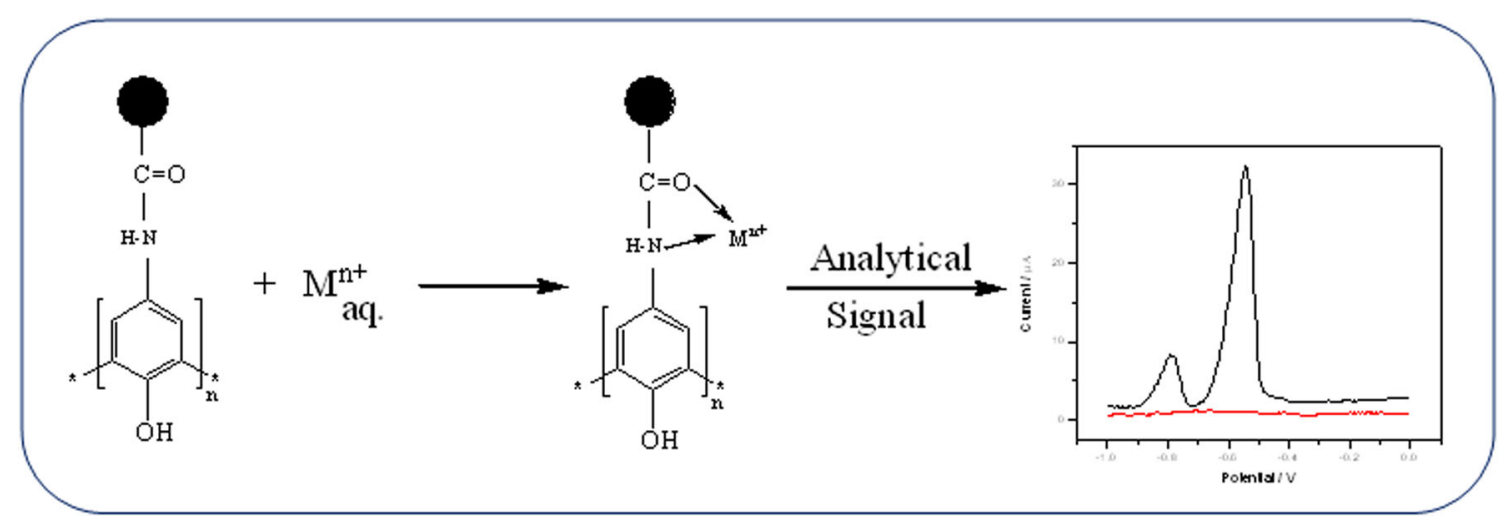

Scheme 4 Schematic representation of binding and complexation mode of modifier with analyte 


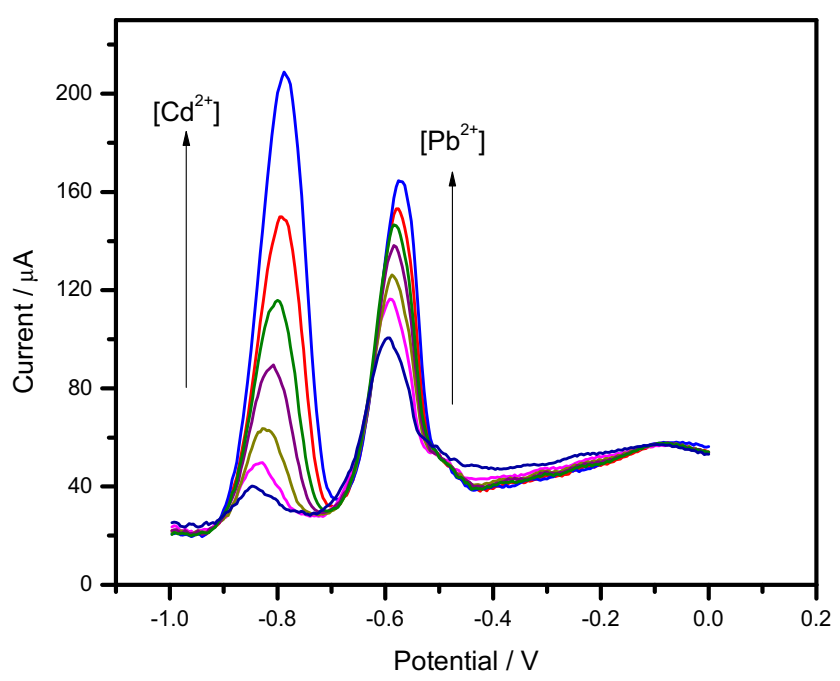

Fig. 7 Overlaid stripping voltammograms of the modified electrode in presence of different concentrations of $\mathrm{Pb}^{2+}$ and $\mathrm{Cd}^{2+}$ after a deposition time of $300 \mathrm{~s}$ at $-1.20 \mathrm{~V}$, respectively

regression coefficients of the above equations indicate the linearity and standard deviations in the slope (Table 3ESI).

\section{Interference study}

In order to check the selectivity of the proposed sensor, the effect of interfering ions was studied. Common cations and anions were added into the electrolyte in addition to the analyte species, and the impact of these ions on the analytical signal intensity was studied. The developed sensor showed least interference from most of the common cations and anions due to specific interaction between the moieties of the modifier molecule and the target analytes, i.e., lead and cadmium ions. The effect of interfering ions on the anodic peak current response in presence of $60 \mathrm{pM}$ each of $\mathrm{Pb}^{2+}$ and $\mathrm{Cd}^{2+}$ ions was investigated (Table 1ESI).

\section{Repeatability and long-term storage stability}

The simultaneous measurements of lead and cadmium ions in presence of $60 \mathrm{pM}$ each of these ions were studied five times using the CME following the proposed protocol. The relative standard deviation in the peak current response was found to be 3.1 and $3.5 \%$, respectively. The stripping voltammograms of the modified electrode in presence of metal ions were studied for a period of 3 months, and the deviation in the peak currents obtained was 4.7 and $5 \%$, respectively, for lead and cadmium. These results revealed that the proposed electrode interface could be used repeatedly over a period of time and posses good stability; hence, it can be used for repeated measurements at trace-level concentration.

\section{Application study}

The proposed sensor has been successfully applied to quantify $\mathrm{Pb}^{2+}$ and $\mathrm{Cd}^{2+}$ ions present in battery effluents, wood's alloy, and wastewater samples. Battery effluents and alloy samples were collected from different sources and filtered to remove any colloidal matter present in it. Ten milliliters of real samples was diluted to $100 \mathrm{~mL}$ by adjusting the $\mathrm{pH}$ to 6 , and this solution was added into the electrochemical cell containing modified glassy carbon electrode. The stripping peak currents were measured, and the concentrations were correlated through the standard calibration plots (Table 2 ESI). The real samples were also analyzed by the atomic absorption spectroscopy (AAS) method for comparison purpose. The results obtained by the proposed protocol are in good agreement with
Table 1 Comparison table with other existing sensors

\begin{tabular}{|c|c|c|c|c|c|}
\hline Electrode & $\begin{array}{l}\text { Metal } \\
\text { ions }\end{array}$ & $\begin{array}{l}\text { Deposition time } \\
\text { (s) }\end{array}$ & $\begin{array}{l}\text { Linear range } \\
\left(\mu \mathrm{g} \mathrm{L}^{-1}\right)\end{array}$ & $\begin{array}{l}\text { Limit of } \\
\text { detection } \\
\text { LOD }\left(\mu \mathrm{g} \mathrm{L}^{-1}\right)\end{array}$ & Ref. \\
\hline $\mathrm{Bi}-\mathrm{CPE}$ & $\begin{array}{l}\mathrm{Pb}^{2+} \\
\mathrm{Cd}^{2+}\end{array}$ & 300 & $\begin{array}{l}10-100 \\
10-100\end{array}$ & $\begin{array}{l}0.9 \\
1.2\end{array}$ & [49] \\
\hline Bi-BDD & $\begin{array}{l}\mathrm{Pb}^{2+} \\
\mathrm{Cd}^{2+}\end{array}$ & 120 & $\begin{array}{l}1-20 \\
1-20\end{array}$ & $\begin{array}{l}1.9 \\
2.3\end{array}$ & {$[50]$} \\
\hline EPPG electrode & $\begin{array}{l}\mathrm{Pb}^{2+} \\
\mathrm{Cd}^{2+}\end{array}$ & 240 & $\begin{array}{l}2-200 \\
20-200\end{array}$ & $\begin{array}{l}0.2 \\
0.3\end{array}$ & {$[51]$} \\
\hline Nafion-BHP-CPE & $\begin{array}{l}\mathrm{Pb}^{2+} \\
\mathrm{Cd}^{2+}\end{array}$ & 300 & $\begin{array}{l}2-10.4 \\
1-5.6\end{array}$ & $\begin{array}{l}0.62 \\
0.17\end{array}$ & {$[52]$} \\
\hline $\begin{array}{l}\text { Bi/PANI-MES/ } \\
\quad \text { GCE }\end{array}$ & $\begin{array}{l}\mathrm{Pb}^{2+} \\
\mathrm{Cd}^{2+}\end{array}$ & 300 & $\begin{array}{l}0.1-30 \\
0.1-20\end{array}$ & $\begin{array}{l}0.05 \\
0.04\end{array}$ & [53] \\
\hline Calixarene-GCE & $\begin{array}{l}\mathrm{Pb}^{2+} \\
\mathrm{Cd}^{2+}\end{array}$ & 300 & $\begin{array}{l}10-120 \mathrm{ng} \mathrm{L}^{-1} \\
10-120 \mathrm{ng} \mathrm{L}^{-1}\end{array}$ & $\begin{array}{l}3.3 \mathrm{ng} \mathrm{L}^{-1} \\
3.5 \mathrm{ng} \mathrm{L}^{-1}\end{array}$ & $\begin{array}{r}\text { Present } \\
\text { work }\end{array}$ \\
\hline
\end{tabular}

$B i-C P E$ bismuth carbon paste electrode, $B i-B D D$ bismuth boron-doped diamond, $E P P G$ edge plane pyrolytic graphite, Nafion-BHP-CPE Nafion-barium hydrogen phosphate-carbon paste electrode, Bi/PANI-MES/GCE Bi, Nafion and 2-mercaptoethanesulfonate (MES)-tethered polyaniline (PANI)/glassy carbon electrode 
the AAS method. Known aliquots of standards were added to the real samples, and its recovery was also studied. The analytical performance of the proposed sensor has been compared with other existing similar protocols (Table 1). The present method showed much better detection limit $\left(\mathrm{ng} \mathrm{L}^{-1}\right)$ than all other methods in which the limit of detection is in the order of microgram per liter. The obtained superior detection limits in the present protocol could be due to complexation between the hydroxyl groups in the lower rim and amide groups in the upper rim of the calixarene and metal ions during the stripping study.

\section{Conclusions}

A novel amino-calixarene-graphite composite material has been used as a modified electrode for the detection of ultra trace $\mathrm{Pb}^{2+}$ and $\mathrm{Cd}^{2+}$ ions by the DPASV technique. The composite material has been easily prepared by microwave irradiation of graphitic carbon in presence of amino-calixarene as a modifier molecule. The chemically modified graphitic carbon has been immobilized on glassy carbon electrode by the dropcasting method and used as a novel electrochemical interface in the measurement of lead and cadmium ions simultaneously. The proposed sensor has shown very low detection limits, respectively, for lead and cadmium ions. The proposed sensor has been successfully applied to measure lead and cadmium ions at trace level from battery effluents, wastewater, and alloy sample matrices. The results obtained by the proposed sensor are in good agreement with the results of the standard protocols.

Acknowledgments The authors acknowledge the financial support from the University Grant Commission (UGC), New Delhi, India. The authors express their gratitude to Karnataka State Pollution Control Board, Bengaluru, India, for providing wastewater samples for analysis.

\section{References}

1. Hutchinson TC, Meema KM (1987) Lead, mercury, cadmium \& arsenic in the environment. Wiley, New York

2. E1 Mhammedi MA, Achakb M, Chtainia A (2009) $\mathrm{Ca}_{10}\left(\mathrm{PO}_{4}\right)_{6}(\mathrm{OH})_{2}$-modified carbon-paste electrode for the determination of trace lead(II) by square-wave voltammetry. J Hazard Mater 161:55-61

3. Lasantha TV, Stoyan B, Nikolay D (2008) Electrochemical method for quantitative determination of trace amounts of lead. Anal Chem 80:2042-2049

4. Guidelines for drinking-water quality fourth ed. (2011) World Health Organization Geneva

5. Mark TF (1986) Electrochemical approaches to trace element speciation in waters: a review. Analyst 111:489-505

6. Li Y, Jiang Y, Yan X, Peng W, Wu Y (2002) A flow injection online multiplexed sorption preconcentration procedure coupled with flame atomic absorption spectrometry for determination of trace lead in water, tea, and herb medicines. Anal Chem 74:1075-1080

7. Ye Q, Li Y, Jiang Y, Yan X (2003) Determination of trace cadmium in rice by flow injection on-line filterless precipitation-dissolution preconcentration coupled with flame atomic absorption spectrometry. J Agric Food Chem 51:2111-2114

8. Yaman M (2005) The improvement of sensitivity in lead and cadmium determinations using flame atomic absorption spectrometry. Anal Biochem 339:1-8

9. Hassan K, Mir FM, Yadollah Y, Mojtaba S (2004) On-line preconcentration and simultaneous determination of heavy metal ions by inductively coupled plasma-atomic emission spectrometry. Anal Chim Acta 509:89-94

10. Kathryn LL (2005) Recent developments in trace element analysis by ICP-AES and ICP-MS with particular reference to geological and environmental samples. Geostandards and Geoanalytical Research 29:7-22

11. Grady H, Deepa GP, Joseph W (2004) Electrochemical sensors for environmental monitoring: design, development and applications. J Environ Monit 6:657-664

12. Joseph W, Baomin T (1993) Mercury-free disposable lead sensors based on potentiometric stripping analysis at gold-coated screenprinted electrodes. Anal Chem 65:1529-1532

13. Xiu-Hua Z, Sheng-Fu W (2005) Determination of ethamsylate in the presence of catecholamines using 4-amino-2mercaptopyrimidine self-assembled monolayer gold electrode. Sens Actuators B 104:29-34

14. Mordechai B, Inna E, Emilia K (1997) The silver electrode in square-wave anodic stripping voltammetry. Determination of $\mathrm{Pb}^{2+}$ without removal of oxygen. Anal Chem 69:4660-4664

15. Beata K, Joanna P (2005) Determination of lead and cadmium at silver electrode by subtractive anodic stripping voltammetry in plant materials containing Tl. Electroanalysis 17:815-818

16. Kangbing W, Shengshui H, Junjie F, Wen B (2003) Mercury-free simultaneous determination of cadmium and lead at a glassy carbon electrode modified with multi-wall carbon nanotubes. Anal Chim Acta 489:215-221

17. Di J, Zhang F (2003) Voltammetry determination of trace manganese with pretreatment glassy carbon electrode by linear sweep voltammetry. Talanta 60:31-36

18. Percy C, Karin YC, Nelci FH, Graciliano ON, Lauro TK (2004) Determination of reduced glutathione using an amperometric carbon paste electrode chemically modified with TTF- TCNQ. Sens Actuators B 100:333-340

19. Gabriela RM, Ramirez-Silva MT, Rosendo LG, Laura G, RomeroRomo M (2005) Electrochemical characterization and determination of mercury using carbon paste electrodes modified with cyclodextrins. Electroanalysis 17:694-700

20. Chengguo H, Kangbing W, Xuan D, Shengshui H (2003) Simultaneous determination of lead(II) and cadmium(II) at a diacetyldioxime modified carbon paste electrode by differential pulse stripping voltammetry. Talanta 60:17-24

21. Honeychurch KC, Hart JP, Cowell DC, Arrigan DWM (2001) Voltammetric studies of lead at calixarene modified screen printed carbon electrodes and its trace determination in water by stripping voltammetry. Sens Actuators B 77:642-652

22. Honeychurch KC, Hart JP, Cowell DC, Arrigan DWM (2002) Voltammetric behavior and trace determination of cadmium at a calixarene modified screen-printed carbon electrode. Electroanalysis 14:177-185

23. Jyh-Myng Z, Annamalai SK, Dong-Mung T (2003) Recent updates of chemically modified electrodes in analytical chemistry. Electroanalysis 15:1073-1087

24. Jean P, Fetah P (2005) Attachment of organic layers to conductive or semiconductive surfaces by reduction of diazonium salts. Chem Soc Rev 34:429-439 
25. Salmanipour A, Taher MA (2011) An electrochemical sensor for stripping analysis of $\mathrm{Pb}$ (II) based on multiwalled carbon nanotube functionalized with 5-Br-PADAP. J Soild State Electrochem 15: 2695-2702

26. Ganjali MR, Asgari M, Faridbod F, Norouzi P, Badiei A, Gholami J (2010) Thiomorpholine-functionalized nanoporous mesopore as a sensing material for $\mathrm{Cd}^{2+}$ carbon paste electrode. J Solid State Electrochem 14:1359-1366

27. Raghu GK, Sampat S, Malingappa P (2012) Chemically functionalized glassy carbon spheres: a new covalent bulk modified composite electrode for the simultaneous determination of lead and cadmium. J Solid State Electrochem 16:1953-1963

28. Frédéric B, Alison JD (2008) Covalent modification of graphitic carbon substrates by non- electrochemical methods. J Solid State Electrochem 12:1231-1244

29. Justin JG (2008) Advances in interfacial design for electrochemical biosensors and sensors: aryl diazonium salts for modifying carbon and metal electrodes. Electroanalysis 20:573-582

30. Malingappa P, Lawrence NS, Compton RG (2002) Homogeneous chemical derivatisation of carbon particles: a novel method for functionalising carbon surfaces. Analyst 127:1568-1571

31. Ling JLW, Ghani SA (2013) Poly(4-vinylpyridine-co-aniline)-modified electrode - synthesis, characterization, and application as cadmium(II) ion sensor. J Solid State Electrochem 17:681-690

32. Intarakamhang S, Schuhmann W, Schulte A (2013) Robotic heavy metal anodic stripping voltammetry: ease and efficacy for trace lead and cadmium electroanalysis. J Solid State Electrochem 17:1535-1542

33. Zarcero SM, Quintanill DP, Sierra I (2015) A disposable electrochemical sensor based on bifunctional periodic mesoporous organosilica for the determination of lead in drinking waters. $\mathrm{J}$ Solid State Electrochem 19:2117-2127

34. Morales GR, Silva TR, Galicia L (2003) Carbon paste electrodes electrochemically modified with cyclodextrins. J Solid State Electrochem 7:355-360

35. Mirjana M, Aleksandra J, Biljana SP, Ivana S, Gordana CM (2012) Exploration of $\mathrm{MnO}_{2}$ /carbon composites and their application to simultaneous electroanalytical determination of $\mathrm{Pb}(\mathrm{II})$ and $\mathrm{Cd}(\mathrm{II})$. Electrochim Acta 74:158-164

36. Diamond D, Nolan K (2001) Peer reviewed: calixarenes: designer ligands for chemical sensors. Anal Chem 73:22 A-29 A

37. McMahon G, O’Malley S, Nolan K, Diamond D (2003) Important calixarene derivatives-their synthesis and applications. ARKIVOC (vii):23-31

38. Mahajan RK, Kaur I, Kumar M (2003) Silver ion-selective electrodes employing Schiff base p-tert-butyl calix[4]arene derivatives as neutral carriers. Sens Actuators B 91:26-31

39. Amit B, Haim T, Ze'ev P, Daniel M (2008) Detection of uranium(VI) in aqueous solution by a calix[6]arene modified electrode. J Electroanal Chem 621:214-221
40. Iwona S, Hanna R, Jerzy R, Philip AG, Colin NW (2006) Ferrocenesubstituted calix[4]pyrrole modified carbon paste electrodes for anion detection in water. J Electroanal Chem 591:223-228

41. Dernane C, Zazoua A, Kazane I, Jaffrezic-Renault N (2013) Cadmium-sensitive electrode based on tetraacetone derivatives of p-tert-butylcalix[8]arene. Mater Sci Eng C 33:3638-3643

42. David CG, Muzaffer I, Donald S (1986) Calixarenes. 18. Synthesis procedures for p-tert- butylcalix[4]arene. J Org Chem 51:742-745

43. Ping-Shan W, Rui-Sen L, Han-Xing Z (1999) Direct synthesis pnitrocalix[4]arene from p-tert-butylcalix[4]arene. Synth Commun 29:2225-2227

44. Ramesha GK, Sampath S (2007) Exfoliated graphite oxide modified electrode for the selective determination of picomolar concentration of lead. Electroanalysis 19:2472-2478

45. Malingappa P, Thippeswamy R (2008) Derivatization and characterization of functionalized carbon powder via diazonium salt reduction. J Solid State Electrochem 12:1411-1419

46. Hongchao Y, Ping M (2008) Determination of cadmium (II) using $\mathrm{H}_{2} \mathrm{O}_{2}$-oxidized activated carbon modified electrode. J Appl Electrochem 38:1623-1627

47. Sun D, Wan C, Li G, Wu K (2007) Electrochemical determination of lead(II) using a montmorillonite calcium-modified carbon paste electrode. Microchim Acta 158:255-260

48. Kokkinos C, Economou A, Raptis I, Efstathiou CE (2008) Lithographically fabricated disposable bismuth-film electrodes for the trace determination of $\mathrm{Pb}(\mathrm{II})$ and $\mathrm{Cd}(\mathrm{II})$ by anodic stripping voltammetry. Electrochim Acta 53:5294-5299

49. Toghill KE, Wildgoose GG, Moshar A, Mulcahy C, Compton RG (2008) The fabrication and characterization of a Bismuth nanoparticle modified boron doped diamond electrode and its application to the simultaneous determination of cadmium(II) and lead(II). Electroanalysis 20:1731-1737

50. Toghill KE, Wildgose GG, Moshar A, Mulcahy C, Compton RG (2008) The fabrication and characterization of a bismuth nanoparticle modified boron doped diamond electrode and its application to the simultaneous determination of cadmium(II) and lead(II). Electroanalysi 20:1731-1737

51. Lu M, Toghill KE, Compton RG (2011) Simultaneous detection of trace cadmium(II) and lead(II) using an unmodified edge plane pyrolytic graphite electrode. Electroanalysis 23:1089-1094

52. Sheela T, Basavanna S, Viswanatha R, Kalachar HCB, Naik YA (2011) Barium hydrogen phosphate modified carbon paste electrode for the simultaneous determination of cadmium and lead by differential pulse anodic stripping voltammetry. Electroanalysis 23: $1150-1157$

53. Chen L, Su Z, He X, Liu Y, Qin C, Zhou Y, Li Z, Wang L, Xie Q, Yao S (2012) Square wave anodic stripping voltammetric determination of $\mathrm{Cd}$ and $\mathrm{Pb}$ ions at a $\mathrm{Bi} / \mathrm{Nafion} /$ thiolated polyaniline/glassy carbon electrode. Electrochem Commun 15:34-37 